\title{
An Inventory of the Aquatic and Subaquatic Plants in SASKWater Canals in Central Saskatchewan, Canada, Before and After the Application of the Herbicide Magnacide
}

\section{J. Hugo Cota-SÁNCHEZ1 and KIRSTEN REMARCHuK}

Department of Biology and Herbarium of the University of Saskatchewan, University of Saskatchewan, 112 Science Place, Saskatoon, Saskatchewan S7N 5E2 Canada

${ }^{1}$ Corresponding author: hugo.cota@usask.ca

Cota-Sánchez, J. Hugo, and Kirsten Remarchuk. 2007. An inventory of the aquatic and subaquatic plants in SASKWater canals in central Saskatchewan, Canada, before and after the application of the herbicide Magnacide. Canadian Field-Naturalist 121(2): 164-167.

This study focuses on the floristic composition of aquatic and semi-aquatic plants in the SASKWater canal system and their potential effect on irrigation systems. A checklist, evaluation, and synthesis of the species identified in this survey before and after the application of the herbicide Magnacide are provided, in addition to a brief discussion of the environmental effects of Magnacide. Thirty-three species in 26 genera within 20 plant families were identified. Two unidentified green algae were also collected. Common aquatics (i.e., green algae, Potamogeton spp., Alisma gramineum, A. plantago-aquatica, Ceratophyllum demersum, and Myriophyllum sibiricum) combined with debris from terrestrial plants were the primary contributors to blockage of irrigation drains. In general, the concentration of Magnacide used in this study had a minor effect on aquatic plant diversity, but effectively reduced plant density. However, the long-term effects of pesticides on the surrounding aquatic and terrestrial environments of the SASKWater irrigation system are unknown.

Key Words: aquatic plant inventory, environmental effect, SASKWater canals, Magnacide, acrolein, Saskatchewan.

Plants are vital to the function of aquatic ecosystems for their role in providing food, oxygen, and habitat for other organisms. However, floating and submerged vegetation along with debris from terrestrial plants may be problematic in different types of water bodies. For example, in shallow lakes, profuse plant growth creates dense mats that prevent the regular movement of watercraft. In addition, aquatic plants, including algae, can significantly reduce the aesthetic value of water bodies. Furthermore, rapid growth of vegetation and deposition of debris in irrigation canals can result in a decline in water flow rates and a subsequent inability to supply water to crops. Hence, the removal of selected aquatic species via physical or chemical methods may be required to improve ecosystem function, aesthetic value, and availability for human consumption.

Aquatic plants can be placed into four broad categories: (1) algae, (2) floating-leaved, (3) submerged, and (4) emergent plants (Shelton and Murphy 1989). Of the four categories listed above, algae are of the greatest concern in canal systems because of the likelihood of interfering with water flow. Algae grow profusely in slow moving, shallow water. Floating-leaved and submerged plants are rooted, with the foliage at or below the water surface. Flowing water or disturbance, such as wind, can uproot plants leading to subsequent obstruction of water flow. Finally, emergent species typically grow in shallow, fluctuating water, such as drainage ditches, canals, rivers, periphery of water bodies, and ponds. Plants in this category are of minor concern in canal systems and in some cases may prevent non- aquatic plant debris from entering the system.

Aquatic species impede water flow by clogging gates, intake screens, valves, and pumps in irrigation and drainage channels (Lancar and Krake 2002). As a consequence, localized flooding may result under high water conditions. In addition, Holm et al. (1969) indicate that abundant vegetation in canals can lead to an excessive loss of water through evapotranspiration. pondweed (Potamogeton L.), Milfoil (Myriophyllum sibiricum), Canada Waterweed (Elodea canadensis), wild celery (Vallisneria L.), and American Eel-grass (Zostera marina L.) are a few of the problematic coarse or large species in shallow aquatic environments (Lancar and Krake 2002).

Of particular interest to this study are aquatic taxa that interfere with canal irrigation systems in central Saskatchewan. Accelerated growth of plants in SASKWater canals restricts the amount of water available for irrigation. Given the clogging effect of aquatic plant growth on water flow, agricultural canals were treated with Magnacide, a volatile algaecide and aquatic herbicide, in which the active ingredient is acrolein (Scorecard 2006*). Acrolein contains two functional groups, a reactive double bond and an aldehyde group (Nordone et al. 1996) and is, in turn, toxic to some organisms (Albariño et al. 2007). However, it is widely used in agricultural canals and water bodies as an herbicide to control aquatic weeds (Burland et al. 1984; Sangodoyin and Smith 1996). The use of high concentrations of acrolein could pose a significant risk to aquatic environments (Nordone et al. 1996); therefore, the controlled application and use of Magnacide and other 
herbicides is highly recommended. Previous studies have shown that toxic residues deposited in soils and water bodies have detrimental effects in the life cycles of local flora and fauna (Sangodoyin and Smith 1996). Thus, even though several sources, e.g., Sangodoyin and Smith (1996); Nordone et al. (1996); Albariño et al. (2007), claim that the transient use of acrolein in agricultural waters at minimal amounts has no negative impact in natural aquatic environments, rigid control must be enforced to prevent ecological damage.

In this study, we investigated the floristic composition of aquatic and semi-aquatic plants in the SASKWater canal system and their potential effect on irrigation systems. Our study is a contribution to the knowledge of Saskatchewan aquatic and sub-aquatic flora and provides a preliminary assessment and synthesis of the species identified prior to and after the application of Magnacide. The potential effect of Magnacide on aquatic flora is also discussed.

\section{Methods}

Compared to most wetland inventories, this survey covers a limited geographic area and a restricted range of wetland flora. The site selection and sampling strategy were designed to survey all major areas of the SASKWater canal system to be evaluated in terms of aquatic vegetation within the Saskatoon Southeast Water Supply Project Location Plan (Brightwater-BlackstrapZelma Reservoir areas; $51^{\circ} 25^{\prime}$ to $52^{\circ} 55^{\prime} \mathrm{N}, 106^{\circ} 15^{\prime}$ to $107^{\circ} 00^{\prime} \mathrm{W}$ ). This system irrigates an estimated area of 20120 acres. The survey sites include locations of Magnacide application by SASKWater personnel at intake screens. Acrolein was directly applied to water in strategic sites to control submersed, floating and emergent aquatic weeds. The herbicide was applied at a concentration of 2.5-5.0 ppm/30 minutes every two weeks from June through August 2005 in an attempt to eradicate aquatic species with excessive growth rates (J. Mander, SASKWater, personal communication). Surveys were conducted before and after the chemical treatment to determine the effect of Magnacide on the taxonomic richness and occurrence of aquatic plants in the canal system. Plant collections were conducted in 25-50 $\mathrm{m}$ areas before and after the point of application. Plants were pressed and identified in the herbarium of the University of Saskatchewan (SASK) using several local and regional references (Hotchkiss 1972; Larson 1993; Johnson et al. 1995; Moss 1996; Vance et al. 1984; Royer and Dickinson 1999). The plants collected were prepared as voucher specimens to serve as a permanent reference of this study in the SASK collection.

\section{Results and Discussion}

The survey indicates that the taxonomic composition of the SASKWater canals includes a total of 33 species in 26 genera and 20 plant families (Table 1). In addition, two different, unidentified, algae were collected (Table 1). Our survey also indicates that no plant species were eradicated from the sites as a result of Magnacide application; that is, the same species were identified before and after the treatment. However, the plant density was noticeably lower after the treatment with Magnacide. Various submerged species including Potamogeton richardsonii, $P$. pectinatus, and the unknown green algae were present in most of the sites surveyed. Other aquatics, e.g., Elodea canadensis and Lemna trisulca, were less frequent and accounted for a smaller proportion of plant biomass in the canal system. Emergent species in the Cyperaceae, Equisetaceae, and Asteraceae do not appear to play a role in impeding water flow, but floating debris from non-aquatic taxa, such as Melilotus albus and Hordeum jubatum, contributes to the clogging of intake screens throughout the canal system.

Based on this survey, it is not possible to determine a single species that adversely affects water flow by clogging intake screens in the SASKWater canal systems. A combination of common aquatic plants (Potamogeton spp., Alisma gramineum, A. plantago-aquatica, Ceratophyllum demersum, and Myriophyllum sibiricum), which are frequently dislodged by flowing water or wind, are the primary contributors to blockage of drains and intake screens. The presence of large, coarse water pondweeds such as Potamogeton spp. and other filamentous species in SASKWater canals is undesirable because their accumulation affects the regular water flow. A similar situation has been reported in the Alberta irrigation systems (Burland and Catling 1986). In addition, green algae are common and are presumably the greatest problem in clogging the intake screen systems because of their filamentous nature and massive growth. Furthermore, some plants or fragments from non-aquatic plants, particularly Melilotus albus and Hordeum jubatum, are involved in reducing water flow because the species tend to concentrate near the uptake areas, especially in the vicinities of mowed ditches along the canals.

Since this survey is mainly concerned with the floristic composition of the SASKWater canal system and the probable effect of some species on irrigation canals, only general comments can be made regarding the chemical treatment and subsequent effect in the aquatic and subaquatic plants. In general, the use of Magnacide at the concentration previously specified appears to have a minor effect on aquatic plants because species diversity before and after the application remained similar. This suggests that the amount of chemical applied is too low to notably reduce the growth and development of aquatic plants and possibly other nontarget organisms. Acrolein is a contact herbicide; therefore, the root system is not damaged and plants quickly resume growth. This leads to the frequent re-application of acrolein (J. Mander, SASKWater, personal communication). Other studies, [e.g., Bowmer and Sainty (1977)], have shown that acrolein is effective in controlling aquatic plant growth, but no concentration rates are given. On the other hand, Sangodoyin and Smith 
TABLE 1. Taxonomic list of the inventory of plants in the SASKWater canal system in south central Saskatchewan. The arrangement is alphabetical by family, then by genus and species.

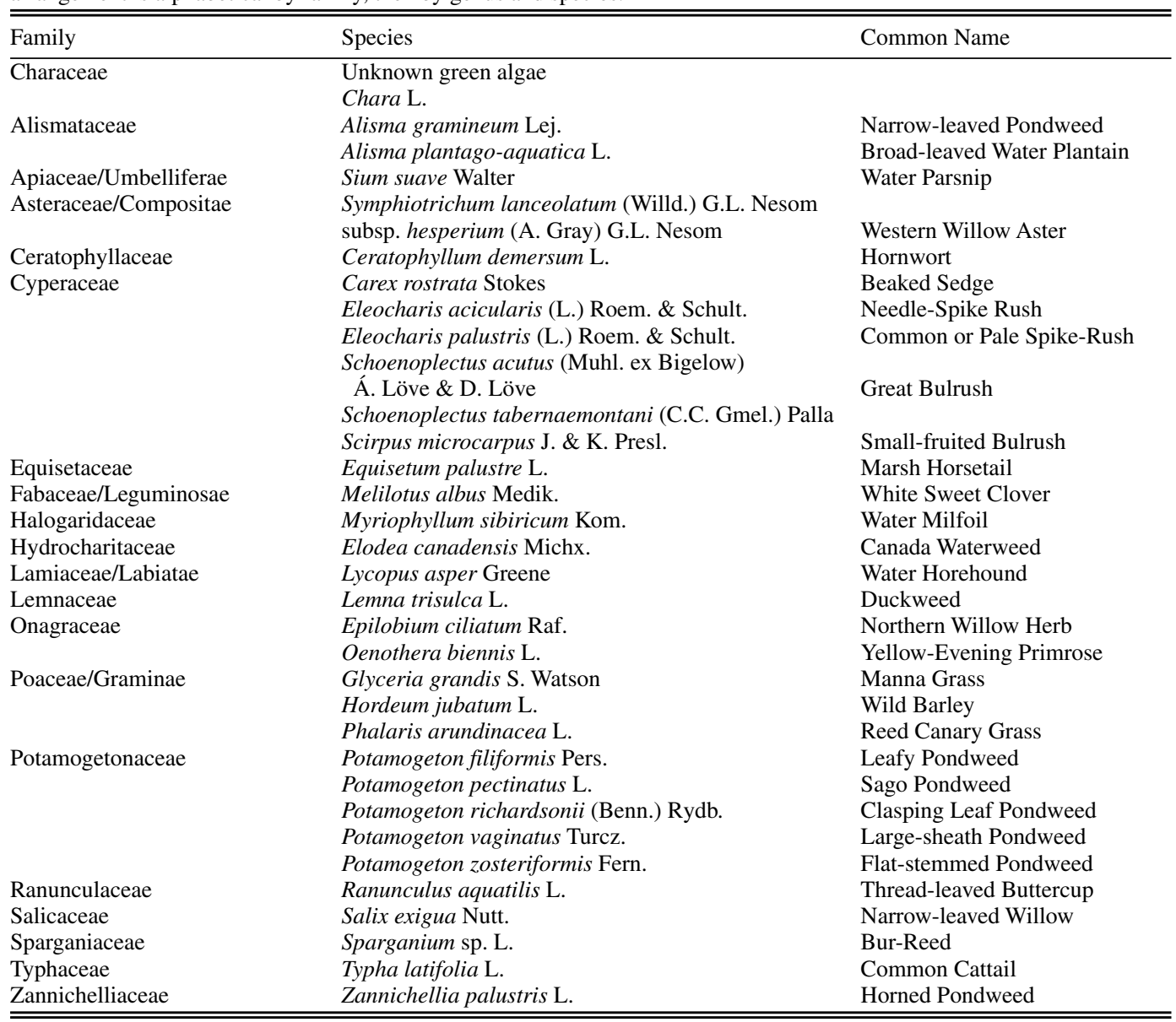

(1996) caution that low concentrations of pesticides and agricultural chemical on surface waters have potential effects on fisheries and aquatic environments, but conclude that Canadian water sources in general exhibit concentrations of pesticides below the guideline limits, which suggests the proper use and handling of pesticides and herbicides in Canada. Nonetheless, more detailed research is required to draw conclusions on water quality issues.

Considering the losses and adverse effects to farming activities caused by obstructed canal systems, the control of aquatic plants is necessary in water bodies, particularly in areas with intake screens, so that irrigation systems can be most efficiently utilized. In addition to the chemical methods currently used for the eradication of aquatic plants, new research to implement a biological control program (involving perhaps an herbivorous species) of aquatic plants in irrigation canals should be conducted. Since numerous nonaquatic species clog irrigation systems, in our view, the most effective, environmentally friendly, and inexpensive strategy for maintaining levels of water flow for irrigation is to periodically manually clean intake screens and surrounding areas. Nonetheless, cautious and planned applications of chemicals such as acrolein (Bowmer and Sainty 1977), Endothall (Sisneros et al. 1998), and Hydrothall (Corbus 1982) may be effective to control excessive growth levels of species such as Potamogeton pectinatus and filamentous algae species.

Since several native, relatively poorly represented species are characteristic of these ecosystems, consistent monitoring is recommended to preserve wild natural resources. Furthermore, the long-term effects of pesticides on the surrounding aquatic and terrestrial environments of the SASKWater irrigation system are unknown. The current challenge is to assess the use of herbicides, in particular the long-term effect and impact of Magnacide residues, in the water quality, environment, and diversity of the wetland flora and fauna in Saskatchewan and other Canadian ecosystems. 


\section{Acknowledgements}

We thank SASKWater personnel, in particular K. Berkers for help with surveys, J. Mander for comments and for showing the canal system, and two anonymous reviewers for their comments on the manuscript. We also thank the personnel of the Herbarium of the University of Saskatchewan (SASK) for their assistance.

Documents Cited (marked $*$ in the text)

Scorecard: The Pollution Information Site. http://www. scorecard.org/chemical-profiles/summary.tcl?edf_sub stance_id=107-02-8. Site visited 22 May 2006.

\section{Literature Cited}

Albariño, R., A. Venturino, C. M. Montagna, and A. M. Pechen D'Angelo. 2007. Environmental effect assessment of Mangnacide ${ }^{\circledR} \mathrm{H}$ herbicide at Río Colorado irrigation channels (Argentina). Tier 4: In situ survey on benthic invertebrates. Environmental Toxicology and Chemistry 26: 183-189.

Bowmer, K. H., and G. R. Sainty. 1977. Management of aquatic plants with acrolein. Journal of Aquatic Plant Management 15: 40-46.

Burland, R., and P. M. Catling. 1986. Vascular aquatic weeds in Alberta. Pages 1-4 in Canadian Chapter Aquatic Plant Management Society 1. Calgary, Alberta.

Burland, G. R., M. D. O'Shea, D. Stix, and R. Veger. 1984. Investigation into the behaviour of Magnacide $\mathrm{H}$ in Alberta irrigation canals. Alberta Environment Pesticide Chemicals Branch, Edmonton, Alberta.

Corbus, F. G. 1982. Aquatic weed control with Endothall in a Salt River Project Canal. Journal of Aquatic Plant Management 20: 1-3.

Holm, L. G., L. Weldon, and R. D. Blackburn. 1969. Aquatic weeds. Science 166: 699-709.

Hotchkiss, N. 1972. Common Marsh, Underwater and Floating-leaved Plants of the United States and Canada. Dover Publications Inc. 124 pages.
Johnson, D., L. Kershaw, A. MacKinnon, and J. Pojar. 1995. Plants of the Boreal Western Forest and Aspen Parkland. Lone Pine Publishing, Edmonton, Alberta. 392 pages.

Lancar L., and K. Krake (reviewers). 2002. Aquatic weeds and their management. International Commission on Irrigation and Drainage, USA. 71 pages.

Larson, G. E. 1993. Aquatic and Wetland Vascular Plants of the Northern Great Plains. General Technical Report RM-238. U.S. Dept. Agriculture, Forest Service, Rocky Mountain Forest and Range Experiment Station, Fort Collins, CO. 681 pages.

Moss, E. H. 1996. Flora of Alberta, $2^{\text {nd }}$ Edition. Revised by J. C. Packer, University of Toronto Press, Toronto, Ontario. 687 pages.

Nordone, A. J., R. Matherly, B. Bonnivier, R. Doane, H. Caravello, S. Paakonen, W. Winchester, and R. A. Parent. 1996. Effect of Magnacide ${ }^{\circledR} \mathrm{H}$ herbicide residuals on water quality within wildlife refuges on the Klamath Basin, CA. Bulletin of Environmental Contamination and Toxicology 56: 964-970.

Royer, F., and D. Dickinson. 1999. Weeds of Canada and Northern United States. Lone Pine Publishing, Edmonton, Alberta. 434 pages.

Sangodoyin, A. Y., and D. W. Smith. 1996. Review of information on pesticide residues in the Canadian environment. The Environmentalist 16: 187-196.

Shelton, J. L., and T. R. Murphy. 1989. Aquatic Weed Management: Control Methods. Southern Regional Aquaculture Center, Publication 360. 2 pages.

Sisneros, D., M. Lichtwardt, and T. Greene. 1998. Low-dose metering of endothall for aquatic plant control in flowing water. Journal of Aquatic Plant Management 36: 69-72.

Vance, F. R., J. R. Jowsey, and J. S. MacLean. 1984. Wildflowers Across the Prairies. Western Producer Prairie Books, Saskatoon, Saskatchewan. 214 pages.

Received 10 July 2006

Accepted 23 May 2008 